\title{
The Impact of Organisational Commitment and Demographic Variables on Organisational Citizenship Behaviour
}

\author{
Raymond Toga* \\ Daniel A Khayundi \\ Themba Q Mjoli \\ Department of Industrial Psychology, University of Fort Hare, \\ Private Bag X1314, Alice, 5700, South Africa \\ *Email: raytoga@gmail.com
}

\section{Doi:10.5901/mjss.2014.v5n2p643}

\begin{abstract}
Organisational citizenship is regarded as one of the most important factor that enhances organisational effectiveness. The main purpose of this study was to explore the impact of organisational commitment on organisational citizenship behaviour (OCB). Demographic factors, such as, age and gender effects on organisational citizenship behaviour of University employees were also examined. The study employed a quantitative research design. A stratified random sample of 68 academic and non academic staff participated in this study. A self administered questionnaire was used for data collection. The questionnaire consisted of three subsections: a self-designed biographical data questionnaire. To measure organisational commitment, Meyer and Allen's (1997) 12-item five-point Likert-type rating scale was used. To measure organisational citizenship behaviour, Podsakoff, Mackenzie, Moorman and Fetter (1990) 27-item five-point Likert-type rating scale was used. Data analysis was done by means of descriptive statistics, Pearson Product Moment Correlation and t-test. The results indicated the view that organisational commitment impacts positively in enhancing the organisational citizenship behaviour of the employees. The findings also revealed that age and gender play no role in the practice of employees' organisational citizenship behaviour. The practical implications of this study; in order to succeed on its mission managed should increase the levels of organisational citizenship behaviour in their employees by consistently recognizing employees who engage themselves in such behaviour.
\end{abstract}

Keywords: organisational commitment, age, gender, organisational citizenship behaviour.

\section{Introduction}

Organisational citizenship behaviour (OCB) describes actions in which employees are willing to go above and beyond their prescribed role requirements. It is an individual behaviour that is discretionary, not directly or explicitly recognized by the formal reward system, and that in the aggregate promotes the effective functioning of the organisation. According to Mearaj (2010), utilizing current resources is one of the factors for the success in any organisation, and in order to achieve the highest utilization; managers should understand the different types of individual behaviour inside the organisation. Aamodt (2007) adds that employees who are committed and satisfied with the organisation are more likely to attend work, stay with an organisation, arrive at work on time, perform well and engage in behaviours helpful to the organisation. The above statements show the importance of OCB in improving organisational effectiveness and helping the organisation achieve its overall goals.

Research on Organisational Citizenship Behaviours (OCB) has been extensive since its introduction close to 30 years ago (Bateman \& Organ, 1983). The vast majority of OCB research has focused on the effects of OCB on individual and organisational performance. OCBs are positively correlated with both job satisfaction and organisational commitment (Podsakoff, Mackenzie, Paine \& Bachrach, 2000). According to LePine, Erez and Johnson (2002), organisational commitment has been discovered to be an important predictor or antecedent of OCB. Thus in this research the association between $\mathrm{OCB}$ and organisational commitment is investigated.

OCB is considered to be one of the most important types of behaviour. Each organisation is always seeking ways to increase the productivity of their employees and encouraging positive behaviour in the work environment. Effective organisational functioning requires employees not only to perform their prescribed roles, but to also engage in behaviours 
that go beyond their formal obligations. OCB is also viewed as desirable because such behaviour is thought to increase available resources and decrease the need for more formal and costly mechanisms of control. Based on existing research, it appears that organisations and managers should be interested in encouraging employee citizenship behaviours (Becton, Giles \& Schraeder, 2008).

While the global research on OCB is conducted in other cultures or developing world, the results cannot be applied directly to organisations in the underdeveloped nations on a local basis. Therefore, there in a need for new studies required in order to understand OCB locally and analyze the differences and to formulate a clear idea about the challenges faced when applying OCB practices locally (Kreitner \& Kinicki, 2010). Thus this study focuses on studying organisational commitment, age and gender effects on organisational citizenship behaviour of tertiary institution employees in the University of Fort Hare, Alice main campus.

Researches have shown that low OCB does not only affect voluntary activities, but also the organisational duties of the employees. Employees with low OCB are more likely to refuse to perform their tasks than those with high OCB. Furthermore employees with low OCB tend to leave the organisation, this is in support with the research conducted by Mearaj (2010) states that is has been proven that there is a link between low OCB and lack of organisational commitment.

Organisational citizenship behaviours are discretional workplace behaviours that exceed one's basic job requirements (Organ, 1990). Developing organisational citizenship leads to employees with high job satisfaction hence improving the overall performance of the organisation. Examples of such behaviour include; act of helpfulness, gesture of goodwill and cooperation among organisational colleagues. There are quite a number of ways that organisations can benefit from OCB. Results conducted previously indicated that commitment is a predictor of organisational citizenship behaviour because it significantly impacts OCB (Liu, 2007).

According to Cohen and Vigoda (2000) some of the benefits of OCBs include: improved co-worker and managerial productivity; superior efficiency in resource use and allocation; reduced maintenance expenses; and improved organisational attractiveness for high-quality new recruits. For many organisations to survive in this current competitive global environment, they have to implement policies that will encourage and promote OCB.

\subsection{Problem statement}

Most organisations today to survive must achieve high performances in the contxt of a competitive and complex global environment (Schemerhorn, Hunt \& Osborn, 2004). Without OCB many organisations are not able to maintain their competitive advantage. OCB influences job performance and other relevant outcomes such as turnover and absenteeism. Thus the impact of organisational commitment must be identified so as to encourage OCB in the organisation.

OCB is important for effective functioning of an organisation because its ultimate goal is to make all the employees work toward achieving the organisation's goals and objectives rather than accomplishing their duties. As a result this would get the job done effectively and efficiently, without the limitation and delay caused by having the management involved to solve each and every problem. OCB is critical for these organisations in order for the employees to take the initiative to solve and difficulty that faces them with no management intervention or overhead. In order to embrace OCB, these organisations need to know the exact factors that affect OCB. And while the factors that affect OCB are known, it is not clear if this relationship would be valid in tertiary institutions where they have their own unique culture; this is why these organisations need to investigate these factors.

Podsakoff et al. (2000) cautioned: 'Cultural context many affect the forms of citizenship behaviour observed in organisations'. Very few studies have been conducted on the impact of organisational commitment and demographic variables on citizenship behaviour especially in tertiary institutions. Because OCB is helpful and involves constructive behaviours, which ultimately beneficial to the employing organisation, it is important to identify the antecedents of OCB within the tertiary institution work context.

Therefore, the current study focused on the effects of organisational commitment and some demographic variables (age and gender) on citizenship behaviour at the University of Fort Hare.

\subsection{Research objectives}

- To investigate the impact of organisational commitment on organisational citizenship behaviour.

- To examine if ages of employees have a relationship with the practice of organisational citizenship behaviour. 
- To identify if gender influences the practice of organisational citizenship behaviour.

- To give recommendations to the management on the effects of organisational commitment and demographic variables on employees' organisational citizenship behaviour based on the research findings.

\subsection{Hypotheses}

In pursuit of the above mentioned objectives the following hypotheses have been formulated.

- Organisational commitment positively influences organisational citizenship behaviour.

- Age positively influences organisational citizenship behaviour.

- Females practices organisational citizenship behaviour more than males.

\section{Literature Review}

\subsection{Theoretical framework}

\subsubsection{Psychological contract theory}

Psychological contract represents an individual's perception about the terms and conditions of reciprocal change between him/herslf and another party (Kreitner \& Kinicki, 2010). According to Armstrong (2006), the theory holds that employees expect to be treated fairly as human beings, to be provided with work that uses their abilities to be awarded equitably according to their contribution, to be able to display competence, to have opportunities for further growth, to know what is expected of them, and to be given feedback of how well they are doing. Therefore there is an exchange of individual employee commitment, motivation and task performance beyond expected outcomes by the organisation.

Indeed, according to psychological contract theory, employees who perceive their relation with their employer s primarily instrumental are more likely to restrict their professional obligations to those activities for which they are paid for (Armstrong, 2006). Bratton and Gold (2007) contend that at the heart of the psychological contract theory is an exchange of individual employee commitment, motivation and task performance beyond expected outcomes by the organisation.

Lam (2001) elaborates that these actions which are beyond formally prescribed role and job descriptions, that is, extra role behaviour rather than role behaviour is what is called organisational citizenship behaviour. This is important in organisations because it brings about organisational success through efficient use of resources.

\subsubsection{Social exchange theory}

The theory proposed that employees exhibit positive or negative behaviour as such a response to the treatment they receive from their employers. That is, people reciprocate the advantages that they receive from their organisation (Bolino, 1999). In other words, if employees are satisfied, they will reciprocate by engaging in organisational citizenship behaviour.

According to Diefendorf, Brown, Kamin, \& Lord (2002), organisational citizenship behaviour is influenced by how employees feel about the organisation and the importance of their job to them. A strong social exchange relationship between the employer and employee therefore will help maintain positive working relationships and would elicit positive sentiments such as satisfaction, commitment and trust in employees. This in turn will move employees to engage in organisational citizenship behaviour (Greenberg \& Scott, 1996). From the above information, the social exchange theory promotes good relations between the employer and the employee for mutual benefit. Thus, a conducive work environment should be developed and maintained in order to strengthen organisational citizenship behaviour of an organisation.

Although the social exchange theory has many advantages, it has its fair share of criticism. Miller (2005) argues that the theory reduces human to a purely rational process that arises from economic needs. Miller (2005) further contents that the theory favours openness as it was developed in the 1970s when ideas of freedom and openness were preferred, but there may be times when openness was not best option in a relationship.

\subsection{Significance of the study}

This research study is important to any organisation which wants to create competence organisational effectiveness. The 
results of this study can be used to identify the role of organisational commitment on organisational citizenship behaviour, and how such behaviour can be encouraged in order to improve the overall performance of organisations.

\section{Research Methodology}

\subsection{Research design}

A quantitative research approach using a questionnaire was used to solicit data in order to understand the impact of organisational commitment and some demographic factors (age and gender) on organisational citizenship behaviour. A quantitative methodology abstracts data from the participants into statistical representations rather than textual pictures of the phenomenon. Quantitative studies produce results that are generalizable across contexts, although they neglect the reality of situations (schulz, 2003).

\subsection{Research participants}

The sample consisted of 100 academic and non academic staff from the University of Fort Hare, Alice main campus. Stratified random sampling was used for this research. Stratified random sampling, is a modification of random sampling in which you divide the whole population into two or more strata based on one or more attributes. In this study, the researcher divided the whole population into strata of academic and non-academic staff. To ensure that samples adequately represented the relevant strata, respondents were randomly selected with each stratum.

\subsection{Measuring instrument}

A questionnaire was used to collect data. The questionnaire consisted of three sections. Section A consisted of demographic variables. Section B and C sought information on organisational commitment and organisational citizenship behaviour.

\subsection{Questionnaire administration and response rate}

- The researcher got a letter from the department of Industrial Psychology requesting each head of departments to assist in the distribution of the questionnaire.

- Questionnaire distribution was done in such a way as to cause minimal, if any, disturbance on work performance.

- Discussions were held with heads of departments to stress the anonymity and confidentiality of the information.

One hundred (100) questionnaires were personally distributed by the researcher to selected respondents. Out of the hundred (100) questionnaires distributed, sixty eight (68) were returned fully completed, giving a response rate of $68 \%$.

\subsection{Statistical analysis}

Data was analyzed by means of descriptive and inferential statistical analysis. The relationship between the variables was analysed by means of Pearson Product Moment Correlation and the t-test was used to evaluate the means between two groups (males and females). The researcher also used Cronbach's Coefficient Alpha to assess the reliability of the measuring instruments.

\subsection{Ethical consideration}

Permission was sought and granted by the university authority. Confidentiality was maintained at all levels and times. Participants were informed through a letter sent, which communicated essential information about the research. In addition, voluntary informed consent was sought from the participants. 


\section{Empirical Findings and Discussion}

The research findings were analysed relating them specifically to the research objectives, hypotheses and the research questionnaire. Descriptive statistics were used in this analysis because they are effective ways of depicting relations and trends. Inferential statistics used to test the hypotheses in this study were the Pearson correlation method, chi-square tests and t-tests. The instrument was tested for reliability using Cronbach alpha and the value was 0.852 .

\subsection{Sample description summary}

This study was based on a random sample of 100 academic and non-academic staff members, of which a total of 68 employees participated in the study. A total of $29(43 \%)$ employees were females and $39(57 \%)$ were males. Although most of the respondents are males in this study, females were also well represented. On distribution of respondents by age; $11 \%$ of the respondents were between $18-24$ years, almost half of the respondents $46 \%$ were between ages of 25 34 years, 16\% were between 35-44 years, $12 \%$ were between $45-54$ years, and 15\% were above 55 years of age. This indicated that employees between ages of 25-34 years dominated. This may be possibly due to many people advancing their careers when they reached such stage.

\subsection{Hypotheses testing}

\subsubsection{Hypothesis 1: organisational commitment positively influences organisational citizenship behaviour.}

Firstly, the researcher performed a chi-square test (see table 1) on the data collected by cross tabulating two variables, organisational commitment and organisational citizenship behaviour so as to determine if there was indeed an association between the two variables.

$\mathrm{H}_{0}$ : There is no association between organisational commitment and organisational citizenship behaviour.

$\mathrm{H}_{1}$ : There is an association between organisational commitment and organisational citizenship behaviour.

Table 1: Cross tabulations indicating relations between organisational commitment and organisational citizenship behaviour.

Chi-square test
\begin{tabular}{|l|c|c|c|}
\hline & Value & df & Asymp. Sig. (2-sided) \\
\hline Pearson Chi-square & $711.122^{\mathrm{a}}$ & 624 & .009 \\
Likelihood Ratio & 271.961 & 624 & 1.000 \\
Linear-by-linear Association & 27.940 & 1 & .000 \\
N of Valid Cases & 68 & & \\
\hline
\end{tabular}

From the results in table 1, indicate a Chi-square value of $711.122^{\mathrm{a}}$ and 624 degrees of freedom with a probability value (p-value) of 0.009 . Since the $p$-value is less than 0.05 , it therefore means that we reject the null hypothesis $\left(\mathrm{H}_{0}\right)$ there is no association between organisational commitment and organisational citizenship behaviour and accept the alternative hypothesis $\left(\mathrm{H}_{1}\right)$, there is an association between organisational commitment and organisational citizenship behaviour.

A correlation analysis was done between two variables, that is, organisational commitment and organisational citizenship behaviour. The Pearson Product Moment Correlation was 0.646 . It is very important to note that the probability value (2-tailed) is 0.000 meaning that the correlation is significant since p-value $(0.000)$ is less than 0.05 . This indicates that there is a strong positive correlation between organisational commitment and organisational citizenship behaviour. This means that an increase in organisational commitment results in an increase in organisational citizenship behaviour. This study, therefore, confirms results of previous studies conducted by Mearaj (2010), Aamodt (2007), LePine et al., (2002) and Liu (2007), that organisational commitment has a positive relationship with organisational citizenship behaviour.

Table 2: Correlations between organisational commitment and organisational citizenship behaviour

\begin{tabular}{|l|c|c|}
\hline & BTOTAL & CTOTAL \\
\hline BTOTAL Pearson Correlation & 1 & $.646^{* *}$ \\
Sig. (2-tailed) & 68 & .000 \\
N & 68 & 68 \\
\hline
\end{tabular}




\begin{tabular}{|l|c|c|}
\hline CTOTAL Pearson Correlation & $.646^{\star *}$ & 1 \\
Sig. (2-tailed) & .000 & 68 \\
N & 68 & 68 \\
\hline
\end{tabular}

Key: BTOTAL represents the variables of organisational commitment, while CTOTAL represents organisational citizenship behaviour.

\subsubsection{Hypothesis 2: Age of employee positively influences organisational citizenship behaviour.}

The researcher performed a Chi-square test (see Table 3) on data collected by cross tabulating two variables, age and organisational citizenship behaviour to determine the correlation between the two variables.

$\mathrm{H}_{0}$ : There is no association between age and organisational citizenship behaviour.

$\mathrm{H}_{1}$ : There is no association between age and organisational citizenship behaviour.

Table 3: Cross Tabulation indicating relationship between age and organisational citizenship behaviour.

\begin{tabular}{|l|c|c|c|}
\hline & Value & df & Asymp. Sig. (2-sided) \\
\hline Pearson Chi-square & $97.563^{\mathrm{a}}$ & 104 & .659 \\
Likelihood Ratio & 90.498 & 104 & .825 \\
Linear-by-linear Association & .086 & 1 & .769 \\
N of Valid Cases & 68 & & \\
\hline
\end{tabular}

The results indicate that the p-value $(0.659)$ is greater than 0.05 , therefore it leads to the acceptance of the null hypothesis that there is no association between age and organisational citizenship behaviour. The results are contrary to many previous that may have indicated that older employees exhibit more organisational citizenship behaviour than younger employees. However, the distribution of respondents by age may also have affected the results of this test. This may be because age groups in this study were not equally represented.

Table 4: Correlations between Age and Organisational citizenship behaviour

\begin{tabular}{|l|c|c|}
\hline & CTOTAL & A2 \\
\hline CTOTAL Pearson Correlation & 1 & .036 \\
Sig. (2-tailed) & 68 & .772 \\
N & 68 & 68 \\
\hline A2 Pearson Correlation & .036 & 1 \\
Sig. (2-tailed) & .772 & \\
N & 68 & 68 \\
\hline
\end{tabular}

Key: CTOTAL represents organisational citizenship behaviour and A2 represents age.

A correlation analysis was conducted between age and organisational citizenship behaviour and the correlation was 0.036 . The table above indicates a probability value of 0.772 meaning that there is an insignificant positive correlation. The correlation is also not significant since the $p$-value $(0.036)$ is greater than 0.05 . This therefore leads to the acceptance of null hypothesis and rejection of the alternative hypothesis. This means that an increase in age does not results in an increase in organisational citizenship behaviour. The results of this study are contrary to research results by Kuehn and Al-Busaidi (2002); Wagner and Rush (2000); and Kanungo and Conger (1993), that older employees practice more organisational citizenship behaviour than younger employees.

The results of this study are similar to a study conducted by Lun and Xu (2007) found that there is a negative relationship between age and organisational citizenship behaviour. It is therefore, very important for organisations to encourage organisational citizenship behaviour of all employees despite their ages. Organisations should not discriminate according to age when hiring and should instead look for best qualified candidates for the job.

\subsubsection{Hypothesis 3: Females practice more organisational citizenship behaviour than males.}

According to Dagane (2004), an independent samples t-test is used when one wants to compare the mean score on some continuous variable for two different groups of subjects. An independent samples t-test will tell you whether there is a statistically significant difference in the mean scores of two groups. 
A Levene's test was first conducted to check if the variances of males and females were the same. The first section of the independent samples t-test output give the results of the Levene's test for equally of variances in table 5 below. This test whether the variation of scores for the two groups is the same. The outcome of this test determines which of the t-values in the first section of the test that SPSS provides, is the correct one to be used. Since the Sig. value $(0.586)$ is larger than 0.05 , the first line in table 1 , which refers to equal variances assumed was used. This confirms that the data did not violate the assumption of equal variances.

To assess the difference between males and females, the sig (2-tailed) for equal variances assumed was used in the second section of the t-test (table 6). The t-value (0.582) was above 0.05 , therefore there was no significant difference between the two groups. Therefore it leads to the rejection of the alternative hypothesis, meaning there was no significant difference between organisational citizenship behaviour of males and females. Thus the findings of this study indicate that gender plays no role in organisational citizenship behaviour.

Organisations must not also discriminate prospective employees according to gender. However, it is important to note that due to past injustices in South Africa were the study was conducted; some jobs may be reserved for women because of the introduction of new labour systems such as Affirmative Action laws.

Table 5: First section of Independent samples t-test.

\begin{tabular}{|l|c|c|c|c|}
\hline & \multicolumn{2}{|c|}{ Levene's test for equality of variance } & \multicolumn{2}{c|}{ t-test for equality of means } \\
\hline & $\mathrm{F}$ & $\mathrm{Sig}$ & $\mathrm{t}$ & $\mathrm{df}$ \\
\hline CTOTAL Equal variance assumed & .299 & .586 & .554 & 66 \\
Equal variance not assumed & & & .541 & 54.688 \\
\hline
\end{tabular}

Key: CTOTAL represents gender

Table 6: Second section of Independent samples t-test

\begin{tabular}{|l|c|c|c|}
\hline \multirow{2}{*}{} & \multicolumn{3}{|c|}{ t-test for Equal of Means } \\
\cline { 2 - 4 } & \multicolumn{3}{|c|}{} \\
\cline { 2 - 4 } & Sig. (2-tailed & Mean Difference & Std. Error Difference \\
\hline CTOTAL Equal variance assumed & .582 & 1.080 & 1.950 \\
Equal variance not assumed & .591 & 1.080 & 1.996 \\
\hline
\end{tabular}

Key: CTOTAL represents gender.

\section{Limitations and Future Research}

It is important to note some of the limitations of this study. The study mainly focused of Fort Hare University, Alice main campus which raises concerns about limited generalisability. As a result the study remains in reality not representative of all other tertiary institutions. Furthermore, since the study was not a longitudinal investigation, the researcher was not able to assess whether changes in the institution's policies will relate to increased organisational citizenship behaviour among the employees. The study used a quantitative research approach. Future studies should also make use of qualitative research approach at it provides room for probing in cases where clarity maybe needed. The current research investigated organisational citizenship behaviour as an outcome of organisational commitment; previous studies have indicated that job satisfaction is a very important predictor of organisational citizenship behaviour. Future research should also study the impact of job satisfaction and organisational commitment on organisational citizenship in tertiary institution in South Africa which would definitely raise the level of knowledge and understanding of citizenship behaviour.

\section{Recommendations and Managerial Implications}

The findings of this research point critically for management to implement policies that will encourage employees to be committed to the organisation. This in turn will increase organisational citizenship behaviour of employees which will lead to a more efficient organisation and help bring new resources into the organisation. Organisational commitment is influenced by psychological contract. In a work environment, the psychological contract represents employee's beliefs about what he/she is entitled to receive in return of what he/she provides to the organisation. Breach of the psychological contract will lead to lower organisational commitment and greater intentions to quit. Commitment to the organisation is enhanced by ensuring that management does not breach the psychological contract and by trying to enhance the level of trust in the organisation.

Management can increase the level of organisational citizenship behaviour by recognizing employees who engage 
in such behaviour. The recognition can came in form of verbal commendation and rewards such as employee of the month. Management can also try and understand employees' individual organisational citizenship behaviour type and create a conducive environment which will encourage employees to continue exhibiting the organisational citizenship behaviour dimensions.

\section{Conclusion}

The study investigated the impact of organisational commitment and demographic factors on organisational citizenship behaviour. The results have indicated that organisational commitment positively influences organisational citizenship behaviour. Therefore management should strive to implement policies that will encourage employees to increase citizenship behaviour so as to increase organisational effectiveness. The results also showed that age and gender play no role in practicing citizenship behaviour by employees in organisations. Organisations should also strive for diversity workforce.

\section{References}

Aamodt, M. G. (2007). Industrial/Organisational psychology: An applied approach. Belmont: Wadsworth.

Armstrong, M. (2006). A handbook of Human Resource Management practice. London: Kogan Page.

Bateman, T. S., \& Organ, D. W. (1983). Job satisfaction and the good soldier: the relationships between affect and employee "citizenship". Academy of Management Journal, 26, 587-595.

Becton, J. B., Giles, W., \& Schreuder, M. (2008). Potential consequences of formally incorporating organisational citizenship behaviour in performance appraisal and reward systems. Employee Relations; Emerald Group Publishing Ltd 30(5), 473.

Bolino, M. C. (1990). Citizenship and impression management. Good soldiers or good actors? The Academy of Management Review, 24(1), 82-98.

Bratton, J., \& Gold, J. (2007). Human Resources Management: Theory and Practice. London: Sage Publishers.

Cohen, A., \& Vigoda, E. (2000). Do good citizens make good organisational citizens? An empirical examination of the relationship between general citizenship and organisational citizenship behaviour in Israel. Administration and Society, 32, 596-625.

Dagane, B. (2004). Basic statistics. Cape Town: Juta.

Diefendorf, J., Brown, D., Kamin, A., \& Lord, R. (2002). Examining the roles of job involvement and work centrality in predicting organisational citizenship behaviours and job performance. Journal of Organisational Behaviour, 23, 93-108.

Greenberg. J., \& Scott, K. S. (1996). Why do employees bite the hand that feeds them? Employee theft as a social exchange process. Research in Organisational Behaviour, 18, 111-166.

Kanungo, R., \& Conger, J. (1993). Promoting altruism as a corporate goal. Academy of Management Review, 7, 37-48.

Kreitner, R., \& Kinicki, A. (2010). Organisational Behaviour. 9th Edition. New York: Mcgraw-Hill//rwin.

Kuehn, K. W., \& Al-Busaidi, Y. (2002). Citizenship Behaviour in a Non-Western Context: An examination of the role of satisfaction, commitment and job characteristics in self-reported OCB. International Journal of Commerce \& Management, 12(2), 107-125.

Lam, S. S. K. (2001). Test-retest reliability and factor structures of organisational citizenship behaviour. Psychology Report, 88(1): 262265.

LePine, L. A., Erez, A., \& Johnson, E. D. (2002). The nature and dimensionality of organisational citizenship behaviour. A critical review and meta-analysis. Journal of Applied Psychology, 87, 52-65.

Liu, C. M. (2007). The early employment influences of sales representatives on the development of organisational commitment. Employee Relations, 29(1),5-15.

Lun, J., \& Xu, H. (2007). How to motivate your older employees to excel? The impact of commitment on older employees' performance in the hospitality industry. Hospitality Management, 26, 793-806.

Mearaj, A. (2010). Organisational citizenship behaviour inside Bahrain organisations. Malaysia: Terbuka.

Meyer, J. P., \& Allen, N. J (1997). Commitment in the workplace: Theory, research and application. California: Sage Publications.

Miller, K. (2005). Communication Theories. New York: McGraw-Hill.

Organ, D. W. (1990). "The motivational basis of organisational citizenship behaviour". Research in Organisational Behaviour, 12, 43-72.

Podsakoff, P. M., Mackenzie, S. B., Moorman, R. H., \& Fetter, R. (1990). "Transformational leader behaviours and their effects on followers' organisational citizenship behaviours". Leadership Quarterly, 1(2), 107-142.

Podsakoff, P. M., Mackenzie, S. B., Paine J., \& Bachrach, D. G (2000). Orhanisational citizenship behaviours: a critical review of theoretical and empirical literature and suggestions for future research. Journal of Management, 26, 513-563.

Schemerhorn, J., Hunt, J. G., Osborn, R. N. (2004). Core concepts of organisational behaviour. New Jersey: Leyn Publishing.

Schulz, S. (2003). Views on the combination of quantitative and qualitative research approaches. Pretoria: UNISA.

Wagner, S., \& Rush, M. (2000). Altruistic organisational citizenship behaviour: Context, disposition and age. Journal of Social Psychology, 140, 379-391. 